\title{
ASPECTOS DA FENOLOGIA DE Copernicia prunifera (Mill.) H.E.Moore NO LITORAL DO PIAUÍ, BRASIL
}

Cynthia Maria Gomes Silva ${ }^{1}$, Renato Oliveira de Souza ${ }^{1}$, Lucas de Souza Cunha ${ }^{1}$, Aurinete Daienn Borges do $\mathrm{Val}^{2}$, Maura Rejane de Araújo Mendes ${ }^{2}$

1. Graduando em Agronomia pela Universidade Estadual do Piauí (UESPI),

Parnaíba -PI, Brasil. cynthia19agro@gmail.com

2. Professora da Universidade Estadual do Piauí (UESPI), Parnaíba - PI, Brasil.

Recebido em: 04/10/2019 - Aprovado em: 30/11/2019 - Publicado em: 15/12/2019 DOI: 10.18677/EnciBio_2019B3

Copernicia prunifera (Mill.) H.E.Moore, conhecida popularmente como carnaúba, é uma planta arbórea, nativa do Brasil, pertence à Família Arecaceae, com ocorrência na região Nordeste. O objetivo desse trabalho foi avaliar os padrões fenológicos da espécie. $\mathrm{O}$ trabalho foi realizado em uma área nativa de carnaubais no município de Luís Correia - PI. Foram selecionados 15 indivíduos adultos, e observados quinzenalmente para registro das fenofases vegetativas e reprodutivas, entre setembro de 2017 e agosto de 2018. Para análise dos dados foram calculados os índices de intensidade de Fournier e de atividade dos eventos fenológicos, e correlacionados com as variáveis ambientais da região. Os eventos vegetativos de emissão e perda de folhas da carnaúba foram contínuos, somente a perda de folhas teve correlação forte com velocidade do vento, fato que mostra que essa fenofase é sincrônica. A floração ocorreu durante o ano, com correlação significativa negativa para a umidade e radiação solar, e correlação significativa positiva para temperatura, indicando que a floração ocorre no período de maior temperatura e menor radiação. A frutificação ocorreu de maneira moderada, com correlação significativa para temperatura. Copernicia prunifera tem os eventos vegetativos assincrônicos, com perda de folhas e emissão de folhas novas durante todo o período, a floração e a frutificação ocorrem com maior intensidade em períodos de maior temperatura e menor umidade relativa. São necessárias mais observações para melhorar a definição de fenologia dessa espécie.

PALAVRAS-CHAVE: Arecaceae, variáveis climáticas, eventos fenológicos

\section{PHENOLOGY FEATURES OF Copernicia prunifera (MILL.) H.E.MOORE IN PIAUÍ COAST, BRASIL}

\begin{abstract}
Copernicia prunifera (Mill.) H.E.Moore, knowing as carnaúba, is an arboreal and native plant belonging to the Family Arecaceae, occurring in Northeastern Brazil. The aim of this study was to evaluate the phenological patterns of this species in a native area of carnaubas in the municipality of Luís Correia, Piauí State. Fifteen adult individuals were observed biweekly to register the vegetative and reproductive phenophases, between Spetember 2017 and August 2018. For data analysis were
\end{abstract}


calculated the Fournier index and the activity of phenological events, and then correlated with environmental variables on the study area. Vegetative events of leaf emission and loss have strong correlation with wind speed, which shows that phenophase is synchronic. The flowering occurred during the entire year with a negative correlation for humidity and solar radiation, and a posivite correlation for temperature, indicating that flowering occurs in the period of lowest radiation and highest temperature. The fruiting occurred moderately with significant correlation for temperature. Copernicia prunifera has assychronic vegetative events with leaf emission and loss during a year. Flowering and fruiting occurred with greater intensity during highest temperature and lower relative humidity periods. Further observation is needed to better define the phenology of this species.

KEYWORDS: Arecaceae, environmental variables, phenological events.

\section{INTRODUÇÃO}

Copernicia prunifera (Mill.) H.E. Moore, conhecida popularmente como carnaúba, é uma planta arbórea, com caule do tipo estipe que pode atingir de 10 a 15 metros de altura e diâmetro entre 15 a 25 centímetros (VIEIRA, 2015). Possui crescimento lento, cerca de 30 centímetros por ano, com primeira floração registrada entre 12 e 15 anos de idade e apresenta fácil propagação por meio de sementes. As folhas em forma de leque de até 1,5 metros de comprimento têm lâmina recoberta por cera (ALVES; COELHO, 2009). Os indivíduos mais frondosos podem conter até 60 folhas por árvore, embora isso esteja relacionado a períodos chuvosos com boa precipitação pluviométrica (ALVES; COELHO, 2009).

Trata-se de uma planta nativa do Brasil, pertence à Família Arecaceae, com ocorrência na região Nordeste, especialmente nos vales dos rios da região da Caatinga, entre os estados do Piauí, Ceará e Rio Grande do Norte (SILVA et al., 2015). No Piauí, as principais regiões de ocorrência de carnaubais são as microrregiões de Campo Maior, Baixo Parnaíba Piauiense, Litoral Piauiense, Valença do Piauí, Alto Médio Canindé, Picos e Floriano (ALVES; COELHO, 2009).

A espécie apresenta importância social, ambiental e econômica (COSTA; GOMES, 2016). Do ponto de vista social, destaca-se pela geração de ocupação do meio rural, enquanto na questão ambiental, colabora com equilíbrio dos ecossistemas naturais (COSTA; GOMES, 2016). As potencialidades econômicas da carnaúba são inúmeras, que inclui desde a raiz, estipe, folhas, pecíolos, fibras e frutos para fabricação de produtos artesanais e industriais (CARVALHO, 2009). O principal produto com valor comercial na cadeia produtiva é o pó cerífero, extraído das folhas (FERREIRA, 2013; ROCHA et al., 2015). O Piauí é considerado o maior produtor de pó cerífero do Brasil (128.528 toneladas), somando a produção de 1990 a 2006 (ALVES; COELHO, 2009). Tamanha potencialidade tem causado redução das populações naturais, especialmente pela falta de programas que incentivem 0 plantio de carnaúbas na região semi-árida (PEREIRA et al., 2014), bem como pelo caráter extrativista da coleta de seus recursos.

Alguns fatores são determinantes para a produtividade do pó cerífero, tais como os fatores abióticos, como clima e solo, que podem influenciar na expressão fenotípica da espécie (FERREIRA, 2013). Entretanto, fatores relacionados à morfologia e fisiologia da planta, a exemplo do tipo e número de folhas, comprimento e largura das mesmas, quantidade de pó e estádio de desenvolvimento também influenciam na produção (FERREIRA, 2013). 
Com base no exposto, acompanhar as diferentes fases biológicas da carnaúba pode contribuir com estratégias de conservação da espécie. Segundo Morellato et al. (1995), a fenologia tem sido usada no Brasil para ampliar conhecimentos de diversas áreas das ciências, por exemplo, silvicultura, genética, ecologia, dentre outras. Nos trabalhos fenológicos, determinam-se as datas de floração, frutificação, brotamento e queda de folhas, sempre associando ao conhecimento do ciclo anual das espécies vegetais de interesse (FERREIRA, 2017). Assim, através desses estudos, pode-se avaliar a disponibilidade de recursos fornecidos pelas espécies ao longo do ano (MORELLATO, 1995).

A investigação fenológica também permite compreender as respostas funcionais de determinada espécie às variações ambientais, especialmente à sazonalidade hídrica, como é característico da caatinga, onde as espécies podem apresentar comportamentos fenológicos adaptados às particularidades da região (NUNES, 2018).

A observação dos períodos de floração e frutificação foi adotada desde as civilizações antigas, com objetivo de diferenciar ao longo do ano as plantas fornecedoras de alimentos para o homem, bem como para a fauna (CARVALHO, 2009). Nesse sentido as palmeiras se destacam, por apresentarem grande potencial na alimentação. Existem acompanhamentos fenológicos para algumas espécies da Família Arecaceae, a exemplo de Syagrus romanzoffiana (Cham.) Glassman (jerivá), Bactris gasipaes Kunth. (pupunha), Euterpe edulis Mart. (Jussara) no estado de São Paulo (GARCIA; BARBEDO 2015); Syagrus oleracea (Mart.) Becc. (guariroba) em Goiás (NUNES, 2018); Orbignya phalerata Mart. (babaçu) no Acre (MENDONÇA et al., 2014), entre outros.

Estudos que abordam direta ou indiretamente aspectos fenológicos para Copernicia prunifera são poucos e concentram-se principalmente no estado do Rio Grande do Norte. Sousa et al. (2015), realizaram um estudo etnobotânico e etnoecológico e relatam que os moradores citam períodos de duração controversos para os eventos de floração e frutificação da espécie, embora a maioria da população estudada cita outubro a novembro para floração e frutificação até fevereiro. Rocha et al. (2015), acompanharam além dos períodos reprodutivos, a fenologia vegetativa em uma área de Caatinga do Estado, susceptível a desertificação. Os autores caracterizam os eventos vegetativos assincrônicos, com perdas e renovação foliar ao longo do ano, enquanto os eventos reprodutivos ocorrem em dois períodos no ano. Dessa forma, são necessários novos estudos em outros ambientes do Nordeste, a fim de caracterizar melhor a ecologia da espécie.

Partindo dessa premissa, o objetivo deste trabalho foi avaliar os padrões fenológicos de indivíduos de $C$. prunifera em uma área do litoral do Piauí visando ao conhecimento sobre as estratégias de sobrevivência e a ocorrência das fenofases.

\section{Área de estudo}

\section{MATERIAIS E MÉTODOS}

O trabalho foi realizado em uma área nativa de carnaubais, nas proximidades da praia que recebe o mesmo nome "Carnaubinha", no município de Luís Correia $\mathrm{PI}$. O município está localizado na microrregião do Litoral Piauiense, entre as coordenadas geografias 02052'44"S e 4140'01"W (AGUIAR ; GOMES, 2004). Caracteriza-se por apresentar precipitação média anual de $1.200 \mathrm{~mm}$, definida pelo regime equatorial marítimo e, temperaturas máximas e mínimas de $32^{\circ}$ e $25^{\circ}$, respectivamente (AGUIAR; GOMES, 2004). Segundo classificação de Köppen, o 
clima da região pode ser classificado Aw', tropical, com chuvas distribuídas sazonalmente, com máximas no outono (ROCHA, 2016).

\section{Fenologia}

Foram selecionados 15 indivíduos adultos de Copernicia prunifera com bons aspectos fitossanitários, como copa cheia, com predominância de folhas eretas e verdes e que não apresentavam brocas ao longo do caule. Em seguida, os indivíduos foram georreferenciados e observados quinzenalmente com ajuda de binóculo, para registro das diferentes fases, entre setembro de 2017 a agosto de 2018. Verificaram-se as fenofases reprodutivas: botão floral, floração e frutificação. As fenofases vegetativas seguiram Garcia e Barbedo (2015): folha nova aquela que ainda está totalmente fechada, as verdes e abertas foram denominadas maduras, e como folha velha, as secas aderidas à planta.

Para análise dos dados foram calculados os índices de intensidade e de atividade dos eventos fenológicos de Fournier (1974). Para o primeiro índice, os valores de percentagem das fenofases reprodutivas e vegetativas devem ser enquadrados dentro de uma escala intervalar, semi-quantitativa de cinco categorias (0 a 4). Considerando a intensidade de cada fenofase foi calculada a porcentagem de Fournier através da seguinte fórmula: $\%$ de Fournier $=\Sigma$ Fournier $.100 / 4 . N$. Onde, $\Sigma$ Fournier é a somatória das categorias de intensidade de Fournier dos indivíduos, dividido pelo máximo de intensidade que pode ser alcançado (4) por todos os indivíduos (N) na amostra (Fournier, 1974). Segundo Morellato (1995), quanto maior o número de indivíduos, maior é a sincronia da população. Assim, os eventos são considerados não sincrônicos ou assincrônicos com menos de $20 \%$ dos indivíduos na mesma fenofase; pouco sincrônico ou sincronia baixa entre $20-60 \%$ de indivíduos na fenofase e alta sincronia com mais de $60 \%$ de indivíduos na mesma fenofase (Morellato, 1995).

O outro método utilizado neste estudo foi o índice de atividade. Por meio deste, pode-se constatar a presença ou a ausência da fenofase no indivíduo, sem detalhar a intensidade. Esse método tem caráter quantitativo em nível populacional, indicando a porcentagem de indivíduos da população que está manifestando determinado evento fenológico (Morellato, 1995).

\section{Dados climatológicos}

As fenofases amostradas foram correlacionadas com dados de precipitação, umidade, temperatura, radiação solar, e velocidade do vento por meio da correlação de Spearman. Para estimar a importância dos coeficientes de correlação ( $r$ ), os valores de $r$ entre 0,34 e 0,66 indicam relações de força média ( $r$ fraca), e a partir de 0,67 relações fortes ( $r$ forte) como sugeridos por Cann (2002). Os dados meteorológicos foram obtidos no site do INMET (www.inmet.gov.br) no período correspondido ao trabalho na estação mais próxima da área de trabalho. As análises foram realizadas no software livre Past versão 3.20.

\section{RESULTADOS E DISCUSSÃO}

A análise dos dados fenológicos indicou emissão de folhas novas de forma contínua durante todo o período de observação do trabalho, com variações de 1 a 5 folhas. Não foram observadas diferenças de intensidade entre os meses, com isso o índice de atividade apresentou semelhança com o índice de intensidade. Este padrão de emissão moderada ao longo do ano foi registrado para a espécie por 
Rocha et al. (2015), em uma área de caatinga do Rio Grande do Norte. Com relação às folhas velhas, ou seja, as folhas secas aderidas a planta, o processo se manteve constante, com pico de intensidade na última quinzena de novembro, apresentando queda na primeira quinzena de abril.

Os eventos vegetativos de emissão e perda de folhas da carnaúba foram contínuos no período de observação proposto, sugerindo que os indivíduos são sincrônicos quanto a estas fenofases, fato observado também por Nunes (2018), para outra espécie da Família, a Guariroba (Syagrus oleracea (Mart Becc.) e para Attalea maripa (Aubl.) Mart. (PIRES et al, 2016).

A fase reprodutiva iniciou-se com a emissão de botões florais, e mostrou atividade durante todo o período, com maior intensidade em janeiro e junho, como registrado por Rocha et al. (2015), para a mesma espécie em uma área de caatinga do Rio Grande do Norte. Foi observado também abortamento durante os meses de maior intensidade de precipitação, fato que pode ter comprometido as fenofases de floração e frutificação de alguns indivíduos durante o período avaliado.

A floração ocorreu durante todo o ano moderadamente, com maior intensidade na segunda quinzena de janeiro, seguida pela segunda quinzena de maio (Figura 1) evento que diverge do registrado no Rio Grande do Norte, que aponta o mês de junho o de maior intensidade (ROCHA et al., 2015), para a mesma espécie.

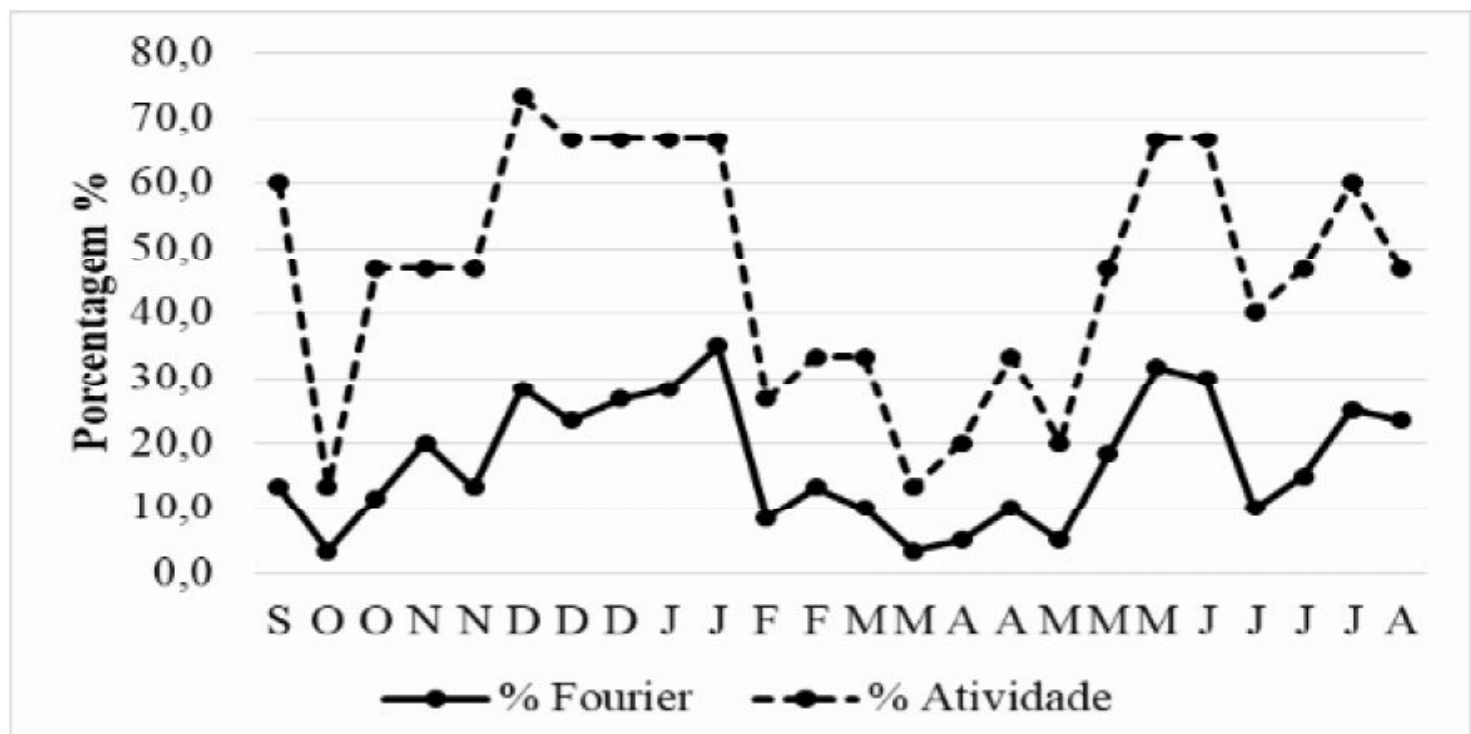

FIGURA 1: Indice de atividade e percentual de Fournier para cachos de flores de Copernicia prunifera.

Para outras espécies de Arecaceae, outros padrões fenológicos foram verificados. Por exemplo, Mendes et al. (2017) verificaram o mesmo mês para pico de floração para a palmeira Buriti (Mauritia flexuosa L.f.). Porém, Rocha et al. (2015), afirmam que para algumas espécies de palmeiras essa diferença se deve aos diferentes períodos de stress hídrico que atrasa ou prolonga a floração e consequentemente a frutificação das espécies.

A frutificação ocorreu de maneira moderada ao longo do ano, os métodos de intensidade e atividade apontaram resultados semelhantes para o pico na primeira quinzena de novembro e queda na segunda quinzena de junho (Figura 2). 


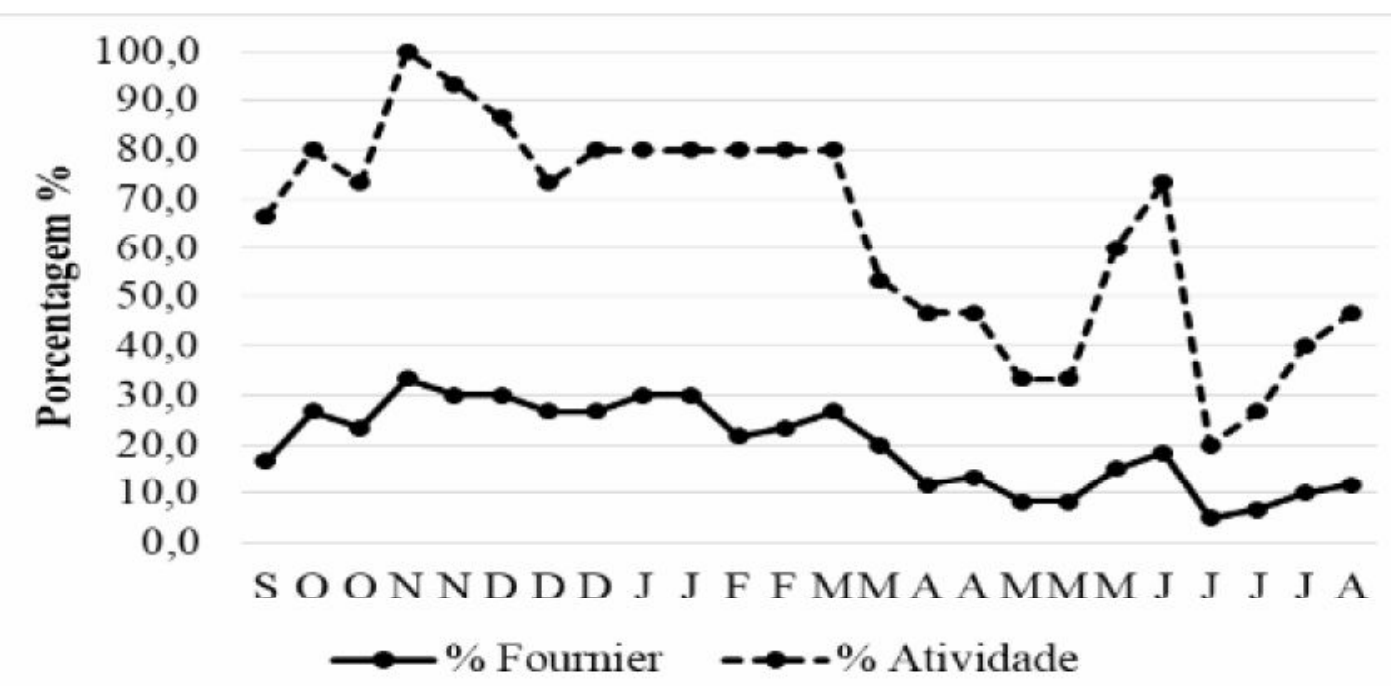

FIGURA 2: İndice de atividade e percentual de Fournier para frutificação de Copernicia prunifera.

Registrou-se também nos meses de maior intensidade de velocidade do vento, maior queda de frutos, enquanto nos meses com maior intensidade de precipitação, os frutos imaturos apresentaram uma espécie de ferrugem, que pode ter a origem de algum inimigo natural da espécie. Neste caso, era seguido por queda. Para a mesma espécie Rocha et al. (2015), registrou em três anos de observação que a frutificação ocorreu mais de uma vez no ano, com maior intensidade nos meses com maior precipitação e o inverso para os meses com menor precipitação, fato semelhante com o presente trabalho. Resultado distinto foi encontrado por Bruno et al. (2019), para as seguintes palmeiras Syagrus flexuosa, Syagrus glazioviana, Syagrus comosa no cerrado brasileiro que apontou os seguintes respectivos meses para o pico de frutificação: maio, setembro e outubro, junho e julho.

As correlações entre os dados fenológicos e as variáveis climáticas indicam que a fenofase folhas novas não foi significativa (Tabela 1). Para as folhas velhas, houve correlação significativa com as variáveis climáticas e correlação forte com velocidade do vento $(r=0,73)$. Um estudo encontrado na literatura sobre fenologia da Copernicia prunifera (Rocha et al., 2015), mostra que houve também correlação significativa da fenofase queda foliar, com as variáveis ambientais e afirma que parte se deve ao mecanismo da planta contra perda de agua e outra a ação mecânica do vento que provoca a quebra da abscisão foliar.

TABELA 1. Resultado do coeficiente da Correlação de Spearman $(r s)(p<0,05)$ entre a Copernicia prunifera e as variáveis abióticas: temperatura, precipitação, umidade, velocidade do vento e radiação. Correlações significativas (rforte $>0,67$; entre $>0,34 \mathrm{e}$ $<0,66$ ).

\begin{tabular}{cccccc}
\hline Fenofases & Tem & Prep & Umi & Vel. vento & Rad \\
\hline Folhas novas & 0,00 & 0,00 & 0,00 & 0,00 & 0,00 \\
Folhas velhas & 0,32 & 0,32 & $-0,53$ & 0,73 & 0,62 \\
Botão & 0,00 & $-0,11$ & $-0,01$ & 0,00 & $-0,37$ \\
Floração & 0,10 & $-0,03$ & $-0,10$ & $-0,01$ & $-0,28$ \\
Frutificação & 0,25 & 0,32 & $-0,46$ & 0,71 & 0,53 \\
\hline ENCICLOPÉDIA BIOSFERA, Centro Científico Conhecer - Goiânia, v.16 n.30; p. 667 & \multicolumn{4}{c}{2019}
\end{tabular}


O florescimento obteve correlação significativa para umidade, temperatura e radiação solar (Tabela 1), fato que se repete para Rocha et al. (2015) que indicam que a floração ocorre no período de maior temperatura e menor radiação.

A frutificação correlacionou-se de forma significativa para todas as variáveis ambientais (Tabela 1), sendo negativa e fraca para umidade, fato semelhante ocorreu no trabalho de Rocha et al. (2015), que constataram que frutos maduros apresentaram correlação negativa e significativa com a umidade relativa. A correlação foi considerada fraca para radiação solar $(r=0,53)$ e forte para velocidade do vento $(r=0,71)$, a correlação ocorreu de forma significativa para temperatura. A frutificação também se correlacionou significativamente com todas as variáveis ambientais em um estudo de Mendes et al. (2017), sobre a fenologia reprodutiva de Mauritia flexuosa na Restinga de Barreirinhas, no Nordeste do Brasil.

Durante o período de observações, foi verificado em alguns indivíduos o abortamento de flores e frutos, como também baixa taxa de produção de frutos maduros e, consequentemente, baixa dispersão das sementes. A baixa produção de frutos pode ser resultado de diversos fatores, como reduzida taxa de polinização, ocorrência de aborto do fruto imaturo e baixa fertilidade do solo.

A intensidade de eventos fenológicos geralmente está associada com fatores bióticos e abióticos (ROCHA, et al 2015). Todos esses fatores estão sujeitos a interferências das mudanças no ambiente físico, de forma que cada espécie ou indivíduos responda diferentemente a um mesmo estímulo. Assim, indica necessidade de realizarem-se acompanhamentos fenológicos de longa duração, para que possa avaliar a maior ou menor interferência de fatores bióticos e abióticos nos padrões fenológicos presentados ao longo de vários ciclos reprodutivos.

\section{CONCLUSÃO}

Copernicia prunifera tem os eventos vegetativos assincrônicos, com perda de folhas e emissão de folhas novas durante todo o período observado. A floração e a frutificação ocorrem com maior intensidade em períodos de maior temperatura e menor umidade relativa. São necessárias mais observações para melhorar a definição de fenologia dessa espécie.

\section{REFERÊNCIAS}

AGUIAR, R. B.; GOMES, J. R. C. (Org.). Diagnóstico do município de Barreiras do Piauí. In: Projeto Cadastro de fontes de abastecimento por água subterrânea - Estado do Piauí. Fortaleza: CPRM, 2004. Disponível em: http://rigeo.cprm.gov.br

ALVES, M. O; COELHO, J. Questões Agrarias, Educação No Campo e Desenvolvimento. Fortaleza. Tecnologia e Relações de Produção no Extrativismo da Carnaúba no Nordeste Brasileiro. Fortaleza: BNB, 2009. P. 1-20. Disponível em: http://www.sober.org.br/palestra/5/509.pdf.

BRUNO, M. M. A; MASSI, K. G; VIDAL, M. M; HAY, J. V. Reproductive phenology of three Syagrus species (Arecaceae) in a tropical savanna in Brazil. Flora. 252 (2019) 18-25. DOI: https://doi.org/10.1016/j.flora.2019.02.002. 
CARVALHO, J. N. Pobreza, emprego e renda na economia da carnaúba. Revista econômica do Nordeste. Piaui. v.2, n.2,371-378, abril-junho,2009. Disponível em: https://ren.emnuvens.com.br/ren/article/view/357

COSTA, V. L; GOMES, A. J. M. Crédito e conservação ambiental no extrativismo da carnaúba (Copernicia prunifera (Mill.) H. E. Moore) no nordeste brasileiro no período de 2007 a 2012. Interações, Campo Grande, MS, v. 17, n. 1, p. 4-14, jan. /mar. 2016. http://dx.doi.org/10.20435/1518-70122016101

FERRERA, T.S; PELISSARO, T.M; EISINGER, M.S; RIGHI, Z.E; BURIOL, G.A. Fenologia de espécies nativas arbóreas na região central do estado do rio grande do sul. Ciência Florestal, Santa Maria, v. 27, n. 3, p. 753-766, jul.-set., 2017 DOI: http://dx.doi.org/10.5902/1980509828608

FERREIRA, C.S; NUNES, J.A.R; GOMES, R.L.F. Manejo de corte das folhas de Copernicia prunifera (miller) h. e. moore no Piauí. Revista Caatinga, Mossoró, v. 26, n. 2, p. 25-30, abr.-jun., 2013. Disponível em: http://periodicos.ufersa.edu.br/index.php/sistema

FOURNIER, L.A. 1974. Un método cuantitativo para la medición de características fenológicas en árboles. Turrialba 24:422-423.

GARCIA, A. V; BARBEDO, C. J. Estudos fenológicos da palmeira Syagrus romanzoffiana (Cham.) Glassman no Vale do Ribeira-SP. Hoehnea. Vol.43. no.1 São Paulo jan/mar. 2015. http://dx.doi.org/10.1590/2236-8906-40/2015

MENDONÇA, C.C; LIMA, A. F; SILVA, G. M; BARBOSA, C. S; FERREIRA, E. J. L; Mapeamento de populações nativas, aspectos fenológicos e potencial de exploração do fruto de babaçu (Orbignya phalerata. Arecaceae) na Amazônia ocidental do Brasil., Enciclopedia biosfera, Centro Científico Conhecer - Goiânia, v.10, n.18; p.17.2014. Disponível em: http://www.conhecer.org.br/enciclop/2014a/AGRARIAS/mapeamento.pdf

MENDES, F. N; VALENTE, R. M; RÊGO, M. M. C; ESPÓSITO, M. C. Fenologia reprodutiva de Mauritia flexuosa $L$. (Arecaceae) em um ambiente de restinga costeira no nordeste do Brasil. Brazilian Journal of Biology. São Carlos, v. 77, n. 1, p. 2937, março de 2017.2 Disponível em <http://www.scielo.br/scielo.php?script=sci_arttext\&pid=S151969842017000100029\& Ing=en\&nrm=iso >. acesso em 01 out 2019. Epub 08 ago 2016. http://dx.doi.org/10.1590/1519-6984.08515.

MORELLATO, L. P; NEGRELLE, B. R. R; REGO, M. G. Fenologia Ferramenta para Conservação, Melhoramento e Manejo de Recursos Vegetais Arbóreo. CDD 578.42 (21. ed.). Embrapa Florestas Colombo, PR 1995. Disponível em: file:///D:/Downloads/Mudan\%C3\%A7as\%20clim\%C3\%A1ticas\%20e\%20os\%20ecoss istemas\%20(3).pdf

NUNES, H. F; REIS, E. F; GUILHERME, F. A. G; PINTO, J. F. N; SILVA, D. F. P. Fenologia reprodutiva da Guariroba em Jataí-GO. Revista Engenharia na 
agricultura. V.26, n.05, p.399-406, 2018. Viçosa, MG, DEA/UFVDOI: https://doi.org/10.13083/reveng.v26i5.895.

PEREIRA, D. S; SOUSA, J. E. S; PEREIRA, S. M; GONSALVES, R. N; BEZERRA, A. M. E. Emergência e crescimento inicial de Copernicia prunifera (Arecaceae) em função da Maturação dos frutos. Journal of Seed Science, v.26, n.1, p 009014,2014. http://dx.doi.org/10.1590/S2317-15372014000100001.

PIRES, H. C. G; ROSA, L. S; CABRAL, B. S; SILVA, V. M; NOGUEIRA, G. A. et al. Padrão Fenológico de Attalea maripa (Aubl.) Mart. em Áreas de Pastagens na Amazônia Oriental. Floresta e Ambiente 2016; 23(2): 170-179. DOI: http://dx.doi.org/10.1590/2179-8087.048313 ISSN 2179-8087 (online)

ROCHA, T. G. F; SILVA, R. A. R; DANTAS, E. X; VIEIRA, F. A. Fenologia da Copernicia prunifera (Aracaceae) em uma área de caatinga do Rio Grande Do Norte. Cerne, v. 21 n. 4. p. 673-682.2015. DOI: 10.1590/01047760201521041758.

SILVA, R. A. R; VIEIRA, F. A; FAJARDO, C. G; ARAUJO, F. S. Padrões alométricos da palmeira carnaúba (Copernicia prunifera (Mill.) H.E. Moore). Nativa, Sinop, v. 03, n. 01 , p. 56-58, jan. /mar. 2015. DOI: 10.14583/2318-7670.v03n01a09 http://www.ufmt.br/nativa

SOUSA, R. F; SILVA, R. A. R; ROCHA, T. G. F; SANTANA, J. A. S; VIEIRA, F. A. Etnoecologia e etnobotânica da palmeira carnaúba no semiárido brasileiro. Cerne, v. 21, n. 4, p. 587-594, 2015. DOI: 10.1590/01047760201521041764

VIEIRA, F. A; SOUSA, R. F; SILVA, R. A. R; FAJARDO, C. G; MOLINA, W. F. Diversidade genética de Copernicia prunifera com o uso de marcadores moleculares ISSP. Agrária- Revista brasileira de ciência agrárias, Recife, v.10,n.4, p. 525531,2015. DOI:10.5039/agraria.v10i4a5040. 